\title{
LA CONSTRUCCIÓN CIENTIFICA DEL MEDTTERRÁNEO: LAS EXPEDICIONES FRANCESAS A EGIPTO, MOREA Y ARGELIA
}

\author{
por \\ MARIA LUSA ORTEGA GAYVEz
}

Universidad Autónorna de Madrid

RESUMEN! En el siglo XIX tres expediciones cientificas auspiciadas por Francia tuvieron como escenario el Mediterráneo: las expediciones a Egipto, Morea y Argelia. Mediante una exposicion de las lineas generales de desarrollo de los tres proyectos expedicionarios, este trabajo pretende aportar algunas reflexiones en torno al contexto politico-cientffico que otorga a cada una de ellas unos caracteres diferenciadores. Ast se analizan las formas de reclutamiento de los cuerpos expedicionarios, las agendas y dispositivos cientfficos de cada expedición en relación con los intereses geoestratégicos y coloniales franceses y algunos de los resultados cientficos más significativos.

Palabras clave. Expediciones cientificas, historia de la ciencia, siglo xax, Francia, Esipto, Grecia, Argelia, Mediterráneo.

ABSTRACT: In nineteenth-century three scientific expeditions promoted by France had Mediterranean Sea as scene: the expeditions to Egypt, Moree and Algeria. By presenting a general overview of expeditions' developments, this article aims to offer some insights into the political and scientific context for the three expeditionary proyects and its relationships with their differentiated features. The paper explores expeditions members recruiting processes, scientific agendas and devises related to french geostrategy and colonial goals and some relevant scientific results.

KEY WORDS: Scientific expeditions, history of science, 19th, France, Egypt, Greece, Algerfa, Mediterranean Sea.

La Expedición francesa que, al mando del general Bonaparte, ocupará Egipto durante tres años (1798-1801) marca el inicio de una acción gala en el Mediterráneo en el siglo XIX. El modelo de esta gloriosa Expedición de Egipto, en el que por primera vez se une al poderoso ejército revolucionario una imponente Comisión de civiles compuesta por los más ilustres cientificos de 
la Francia de la época, tendrá una menos brillante continuación en las dos expediciones mediterráneas que la suceden: la Expedición de Morea (18291931) y la Expedición de Argelia (1839-1842). Respondiendo todas ellas a coyunturas políticas y a proyectos geoestrátegicos muy diferentes, comparten sin embargo la inclusión de las ciencias y la técnicas como aliadas de la conquista y ocupación de territorios.

A pesar de la envergadura y trascencia que las tres expediciones tuvieron tanto en la política francesa de intervención en el Mediterráneo como en la configuración y desarrollo de diferentes disciplinas científicas, no habían recibido hasta el momento la atención que merecen por parte de los historiadores de la ciencia. No obstante, esta situación ha comenzado ha cambiar, en parte gracias al impulso que la Universidad de París VII dió al estudio conjunto de las tres expeciones científicas ${ }^{1}$ mediante la convocatoria de un seminario que, durante dos años, fue convocando a los investigadores de diferentes disciplinas que nos veníamos ocupando de aspectos relacionados con alguna de las expediciones.

El presente trabajo pretende exponer, al hilo de la presentación de los caracteres de los tres proyectos expedicionarios, una serie de consideraciones que retoman algunos de los aspectos que se pusieron de manifiesto durante el citado seminario, pero también, y fundamentalmente, aquéllos que han guiado nuestro trabajo específico sobre la Expedición de Egipto. Nuestras reflexiones se estructurán en dos polos de análisis que creemos permiten abordar y comparar las tres expediciones: en primer lugar, la posibilidad de hablar de un modelo de expedición científica francesa que pueda dar cuenta de los caracteres de los tres proyectos científico-coloniales; en segundo lugar, el análisis de los dispositivos científicos que se ponen en ejercicio tanto en el diseño como en el trabajo sobre el terreno de los científicos expedicionarios y su relación con la construcción de una imagen integrada del Mediterráneo.

\section{¿UN MODELO FRANCÉS DE EXPEDICTÓN CIENTÍFICA?}

Las tres expediciones cientificas abordadas poseen como característica común principal el estar bajo la tutela del Estado. No obstante, su carácter estatal no les confiere en modo alguno la homogeneidad que algunos autores han pretendido percibir. Los tres cuerpos expedicionarios van a poseer significativamente una diferente adscripción ministerial, de la misma forma en que diferirán en la política científica que regirá tanto el proceso de recluta-

\footnotetext{
1 No obstante, a pesar del esfuerzo realizado, no se ha logrado un estudio comparado similar al que Numa Broc acometiera abordando las expediciones de Morea, Argelia y México, trabajo que sigue siendo de obligada referencia. Broc, Numa, «Les grandes missions scientifiques françaises au $\mathrm{XIX}^{\epsilon}$ siècle (Morée, Algérie, Mexique) et leurs travaux géografiques»: Revue d'Historie des Sciences tome XXXIV (1981) 319-358.
}

Hispania, LV//, núm. 192 (1996) 77-92 
miento de sus miembros como el establecimiento de los grupos disciplinares en que se articulan.

La Expedición de Egipto fue organizada por el Ministerio de Exteriores del Directorio, ${ }^{2}$ puesto que el proyecto de conquista del Valle del Nilo se concibe en un marco geoestratégico determinado por la hegemonía británica en el subcontinente indio y por la denominada "Cuestión de Oriente». La inclusión en la campaña militar de todo un cuerpo civil constituido por unos 150 científicos agrupados en la Commission des Sciences et Arts inaugura en Francia el modelo expedicionario aludido, en el que las armas y las ciencias caminan de la mano en la configuración de un nuevo proyecto colonial francés abanderado por la mission civilisatrice, prometéica misión de llevar la civilización al resto del mundo ${ }^{3}$.

No obstante, la labor civilizadora pronto quedará confinada al universo textual de proclamas, actas fundacionales y prefacios históricos, y el «ejército científico» que acompaña a Bonaparte pasará a encarnar la imagen del nuevo savant gestado en el periodo revolucionario, desplegando un saber científicotécnico al servicio de la nación ${ }^{4}$. Bonaparte y los encargados de las gestiones de reclutamiento de los miembros de la comisión científica, principalmente el matemático Fourier y el químico Berthollet - aunque el general Caffarelli du Farga será el director oficial de la Commission-, no escatimarán esfuerzos para atraer a las personalidades más destacadas de la élite científico-técnica francesa: algunos, como Monge, no se resistirán a lo atractivo del viaje; otros, como Cuvier, rechazarán la oferta, recomendando en su lugar al joven y brillante profesor de zoología del Musée d'Histoire Naturelle Etienne Geoffroy Saint-Hilaire. Como reflejan los nombres citados, la excelencia científica constituía el criterio principal de selección. Para asegurar el éxito, se acudió a todas las instituciones científicas más prestigiosas de la Francia revolucionaria. Así, a los nombres citados se unirán destacados profesores de todas escuelas post-termidormianas —como la Ecole de Mines o la Ecole de Pontes et Chaussées-y principalmente de la Ecole Polytechnique, de la que partirán también numerosos alumnos. Igualmente se reclutará miembros del Observatorio de París, al director de la escuela de Aerostatos de Meudon y los ingenieros pertenecientes al ejército de Italia. Sin una estructura disciplinar preconcebida ni un proyecto previo sobre las tareas a acometer, la fundación

2 Un descripción ponnenorizada de la gestación del proyecto desde un punto de vista exclusivamente político puede encontrarse en SIVVEA, Alain, «Bonaparte et Talleyrand: the Origins of the French Expedition to Egypt in 1798\%: American Journal of Arabic Studies II (1975) 1-13.

3 Los origenes intelectuales e ideológicos de la expedición en el pensamiento francés, especialmente en lo que ha venido a denoninarse el «orientalismo islamizante», han sido analizados en LAURENT, Henry, Les Origines Intellectuelles de l'Expédition d'Egypte (1698-1798), Estambul-París 1987. Al mismo autor debemos la última gran obra de referencia sobre la expedición, LAURENS, Henry, L'Expédition d'Egypte (1798-1801), Paris 1989.

4 Cf. OrTega Galvez, María Luisa, «Técnica e Imperialismo: la Aventura egipcia de Bonaparten: ORTEGA, María Luisa, ElENA, Alberto, ORDoÑEz, Javier, Técnica e Imperialismo, Madrid $1993,23-48$.

Hispania, LVI/I, núm. 192 (1996) 77-92 
del Institut d'Egypte en el Cairo a imagen y semejanza del Institut National apenas unas semanas después del desembarco, establecerá las cuatro secciones que agruparán a los miembros más eminentes de la Commission: Ciencias físicas y matemáticas; Historia Natural; Artes y Literatura; y Economía política, división en absoluto proporcional al número de representantes de cada disciplina en la comisión ni a la labor que se desarrollará en el marco de la campaña. La representación de artistas y literatos era muy inferior tanto en calidad como en calidad a la de científicos e ingenieros. Por otra parte, deberemos destacar la ausencia de una sección específica de medicina, que contrasta de forma paradójica con la relevancia que dicha disciplina estaba llamada a tomar durante la expedición: no obstante, los trabajos realizados por el Larrey y Desgenettes, cirujano y médico en jefe respectivamente, conseguirán un lugar en las publicaciones oficiales del Institut, así como en la magna obra de la Description d'Egypte ${ }^{5}$.

Las expediciones científicas de Morea y Argelia no confluyeron de forma espontánea con el modelo egipcio, sino que buscaban conscientemente la emulación de la gesta bonapartiana. Desde el punto de vista científico, el legado de la misma se hará sentir principalmente en el triunfo de la ciencia post-laplaciana en la que el inventariado, la enumeración y clasificación se convertirán en el dispositivo científico por excelencia. Asímismo tomarán de ella la instrumentación de la ciencia como dignificadora y legimitadora de la ocupación militar. Del mismo modo, el deseo de emulación llevará a la publicación de las obras respectivas que recogerán el trabajo científico realizado: Expedition scientifique de Morée, compuesta de cinco volúmenes y Exploration Scientifique de l'Algerie, constituida por treinta y siete. Sin embargo, ni en Morea ni en Argelia la conquista militar y la conquista científica son procesos paralelos como en Egipto. Por otra parte, los mecanismos de selección y reclutamiento de sus miembros hacen patentes las nuevas relaciones de clientelismo científico que comienzan a imperar en el período.

En 1928 nace la idea de enviar a Morea, donde las tropas francesas habían desembarcado en 1927 tras la destrucción del ejército turco en Navarin, una comisión científica siguiendo el modelo de la gloriosa comisión de Egipto. El proyecto pudo ser concebido por el propio Carlos $\mathrm{X}$, reconocido filohelenista, o por el ministro Martignac deseoso de dar lustre a un régimen impopular. Como quiera que fuese, la organización dependará del Ministerio del Interior, en particular del director de ciencias y artes Vizconde de Simeon. Los ministros de la Guerra y de Marina darán pronto su acuerdo para asegurar el transporte y la situación de los científicos sobre el terreno. El Institut de France será consultado para designar a los participantes y para la redacción de las instrucciones: Cuvier, Geoffroy Saint-Hilaire se ocuparán de las ciencias natu-

5 Obra monumental compuesta por veinte volúmenes, nueve de texto entre memorias y descripciones y once de planchas, incluyendo el gran atlas, que recoge todo el trabajo realizado en Egipto adoptando una estructura en cuatro secciones: Antigüedades, Historia Natural y Egipto Moderno. Su conclusión requirió veinte años de duro trabajo; así los volúmenes de la primera edición imperial fueron saliendo a la luz entre 1809 y 1828.

Hispania, LVU/, túm. 192 (1996) 77-92 
rales; Raoul Rochette y Letronne de la historia y la arqueologia. Finalmente, se constituyeron tres secciones asociadas a las academias correspondientes: la Section d'Architecture et de Sculpture asociada a l'Académie des Beaux-Arts; la Section d'Archeologie a l'Académie des Inscriptions; la Section des Sciences Physiques a la Académie des Sciences.

La creación de estas secciones, su asociación directa con las academias y la redacción previa de instrucciones manifestan ya un espíritu diferente al que inspiraba la expedición de Egipto. Por una parte, se intensifica lo que Lewis Pyensson ${ }^{6}$ ha denominado el carácter de "mafias" transdisciplinares que dominan la organización de la ciencia francesa después del declive del modelo laplaciano-napoleónico de organización social de la ciencia: frente a la identidad disciplinaria, las instituciones que educan y emplean a los ciencíficos marcan la comprensión de los mismos en su trabajo en ultramar, y las academias restringen y regulan el nombramiento de los miembros. Por otra, una agenda previamente establecida muestra la mayor dependencia del trabajo del cientifico sobre el terreno.

Siguiendo los consejos del Institut, se nombrarán los directores de cada sección: Abel Blouet, conocido por su restauración de la termas de Caracalla, para la primera; al frente de la sección de arqueología estará Dubois, conservador de antigüedades egipcias del Louvre; la tercera será encomendada a Bory de Saint-Vincent, ambicioso naturalista que ya acompañara a Baudin en su viaje de circumnavegación (1800-1803), y que actuará a todas luces como el «patrón" de la expedicion. Esta estructura y configuración muestra claramente el destierro de las ciencias físico-matemáticas, antiguo pilar políticocientífico en la jerarquización napoleónica.

Numa Broc, confirmando lo que antes apuntábamos, nos habla de las intrigas del reclutamiento del resto de los miembros de la expedición de Morea y cómo las plazas fueron atribuidas más a los favores que al mérito. De hecho, pocos de los nombres de los seleccionados son representativos de la élite científico-técnica. A ellos se unirán, por orden del director del Dépôt de la Guerra, ingenieros-geógrafos con el fin de levantar una carta a gran escala de Morea, entre ellos Puillon de Boblaye, empleado desde 1817 en los trabajos de la nueva carta de Francia y que será secretario en 1834 de la joven Société géologique de France. La expedición, concebida para un año, tan sólo tendrá una duración de seis meses por lo que se refiere al trabajo de comisión, si bien los ingenieros-geógrafos continuarán su trabajo hasta principios de 1831.

Debemos destacar, además, la significativa inclusión de «artistas», pintores y dibujantes, no especializados en el dibujo técnico y topográfico, sino pintores de "historia", esto es, de composiciones ficticias y literarias, y de paisaje, frente al perfil del ingeniero-dibujante que se configura en Egipto. Estos artistas serán convenientemente instruidos por Saint-Vincent quien les dará

6 Pyenson, Lewis, Civilizing Mission: Exact Sciences and Frech Overseas Expansion: 18301940, Londres 1993. 
indicaciones precisas sobre la iconografía buscada: traducir en las planchas el aspecto físico del país, la figura de las montañas y sus rocas. Esto marcará serias diferencias entre la iconografía presentada por los dibujos de Blouet, director de la sección de arquitectura y escultura, y las del colaborador de Saint-Vincent, Prosper Baccuet ? No obstante, toda la empresa tendrá el carácter de unificación entre las artes y la ciencia, aspecto que no había estado presente en Egipto ni se producirá en Argelia.

En 1837 surgirá un nuevo proyecto de expedición científica, esta vez destinada al reconocimiento y exploración, apenas iniciado desde el desembarco en 1830, de las "posesiones africanas» de Francia. Su organización, dirigida por el Ministerio de la Guerra de la Monarquía de Julio, contará también con la participación en el reclutamiento de personal y aportación financiera de otros ministerios. Así, los miembros de la comisión serán recomentados por los ministerios que comparten los costes de la misma: el ministerio de Instrucción pública nombrará a Henri Milne-Edwards como el naturalista; el de comercio propondrá a Augusto Daubrée, entonces alumno de la Ecole de Mines, como geólogo; como encargado de observaciones sedentarias, metereología principalmente, la Academie des Science designó a George Aimé, por entonces profesor de matemáticas en el recién creado Collège d'Alger; finalmente Bory de Saint-Vincent firmará de nuevo como jefe de la Expedición ${ }^{8}$. De hecho, Bory de Saint-Vincent, tras conocer la existencia de dicho proyecto, había enviado a su ministro Guizot una Note sur la Commission exploratrice et scientifique d'Algerie (octubre, 1838), en la que señalaba una perspectiva pluridisciplinar donde la geografía, entendida como geodesia y topografía, se convertiría en la disciplina rectora ${ }^{9}$. A la geografía, vendrían a unirse las ciencias naturales, la arquitectura y la escultura, la lingüística, la estadística, la agricultura y la física, en particular la meteorología.

Bory de Saint-Vincent reagrupará las diversas disciplinas en tres secciones -que no incluyen la de "geografía" que conserva su autonomía. Pero sorprendentemente, y quebrando los modelos expedicionarios anteriores, la distribución no se basará en un criterio disciplinar, sino territorial: la sección marítima o de litoral, compuesta por botánicos, zoólogos, meteorólogos, dibujantes y preparadores; la sección territorial o del interior, compuesta de la misma forma teniendo como base Constantina; la sección nómada, la más completa, tendrá un zoólogo, un botánico-agricultor, un geólogo, un «anticuarion, un pintor-dibujante de paisaje, un dibujante adjunto "para el estudio del hombre», que seguirán los movimientos de las tropas y harán marchar a las ciencias sobre la égida de la guerra. A las diversas secciones se unirán intérpretes y fundamentalmente médicos, cuya labor tendrá un papel desta-

\footnotetext{
7 Sobre todo ello, Cf. PELTRE, Christine, «Les artistes dans l'expédition de Morée» comunicación presentada al seminario L'invention scientifique de la Méditerranée: Egypte, Morée, Algérie, Paris VII, junio de 1993.

B Cf. PYenson, Lewis, op. cit., pág. 88.

9 Cf. Broc, Numa, op. cit., pág. 326.

Hispaniz, LVI/, nùm. 192 (1996) 77-92
} 
cado tanto durante la expedición como en el desarrollo de la ciencia y la polftica coloniales francesas en Argelia durante todo el siglo. La experiencia griega había convencido a Bory de la necesidad de reclutar, siempre que fuera posible, científicos del ejército, considerando además sufiente dos años de trabajos sobre el terreno, otros tantos para la preparación de la publicación. Sin embargo, su proyecto no se adecuará completamente a realidad: nombrado en 1839 director de la Commission exploratrice d'Argérie, tuvo que contar con un personal muy hetereogéneo. Además de los militares ingenieros-geógrafos que ya se encontraban trabajando en Argelia, cabe destacar entre los civiles al Dr. Périer, a los naturalistas Fournel, Ravergie y Renou, al arqueólogo Ravoisié, y a ellos viene a sumarse quien se convertirá en el principal rival de Bory de Saint-Vicent: Prosper Enfantin, padre de los saint-simonianos quien, de regreso a Francia después de una estancia de cuatro años en Egipto, se había construído una reputación en asuntos orientales y musulmanes. Sobre el papel, Enfantin debería ocuparse de los trabajos relativos a etnografía, costumbres e instituciones, pero pronto pretenderá ocuparse de todo lo demás, soñando con crear un Institut d'Afrique como el que Bonaparte crease en el Cairo, convertir la expedición en un proyecto más amplio de proyección franco-árabe en Africa y con instaurar una experiencia de colonización "socialista". La comisión realizará sus trabajos sobre el terreno hasta principios de 1843, regresando en su mayoría a Francia, si bien algunos de ellos serán encargados con misiones a Tunez y Marruecos.

Esta presentación general de la génesis y constitución de las tres expedi. ciones francesas que marcan la intervención del país galo en el Mediterráneo en el siglo XIX permiten, ciertamente, hablar en términos bagos de un modelo de expedición científica, que verá su prolongación en la Expedición de México (1864-1867) en un nuevo intento de emular la gesta egipcia por parte de Napoleón III. Si realmente podemos hablar de un modelo, cuya especificidad en relación con otros países, como España, podemos dejar abierta ${ }^{10}$, debemos su invención a la campaña de Egipto: ella es un precedente al que se pretende emular, aunque las condiciones científico-sociales que la conformaron no se reperían como sustrato de las posteriores. El carácter estatal no confiere por sí mismo identidad y, por tanto, unidad a las tres expediciones. La Expedición de Egipto rompe con la tradición del viaje ilustrado del xvIII en el que se recogen especímenes naturales o culturales para su capitalización por el científico en la metropoli, puesto que son científicos de primera talla los que se hallan sobre el terreno; pero, lo que es más importante, altera la producción de los textos, puesto que desde un primer momento la memoria, que anula el escenario y eliminan al actor, es la protagonista; sus miembros, civiles y militares, no poseen el perfil del viajero o expedicionario que, al menos en un principio, podría encarnar una figura como Bory de Saint-Vincent o los anticuarios que le acompañan a Morea, a los que podríamos considerar la reinterpretacíón romántica del científico-viajero ilustrado, sino que representan a la élite de la

10 Dicho aspecto fue abordado por Fermin del Pino en el seminario citado. 
MARIA LUISA ORTEGA GÁLVEZ

ciencia francesa de la época a la que la República ha movilizado en la reconstrucción nacional, tanto física como moral, principalmente en lo que a las ciencias físico-matemáticas se refiere y la integración reclamada por Carnot con su aplicación. El banco de pruebas de las relaciones ciencia-poder que se desarrollarán en el Imperio encarnado en la Expedición de Egipto ${ }^{11}$ no será por tanto repetido en ninguna de la expediciones posteriores: totalmente ausente en Morea, la fuerte jerarquización militar en Argelia también la destingue de la experiencia egipcia. Tampoco conseguirían utilizar, como lo hizo Bonaparte, a sus savants como escenario de su gloria.

\section{DIVERSIDAD DE ESPACIOS Y DISPOSITIVOS CIENTIIFICOS INTEGRADORES}

Otro aspecto que debe anclar nuestra reflexión acerca de las tres expediciones francesas es la diversidad de los espacios que les sirven de escenario: un Mediterráneo oriental otomano, en el caso de Egipto; un Meditarráneo septentrional que ya no lo es y perteneciente a Europa, para la expedición griega; un Mediterráneo magrebí bajo el poder francés, Argelia. Como puede desprenderse de lo hasta ahora expuesto, las tres expediciones responden a intereses geopolíticos muy diferentes, como lo son los territorios a inventariar.

Recordemos que Egipto constituía una provincia del Imperio Otomano con unas características físicas, políticas y culturales muy particulares: por una parte, su práctica independencia administrativa respecto a la Sublime Puerta debida al gobierno mameluco; por otra, la imagen que en Europa prevalecía de la tierra de los faraones, una identidad propia que la convertía en diferente al resto de las provincias otomanas y la más «occidental» de ellas, puesto que había sido la cuna de la civilización. Grecia compartía, de forma aún más radical, este perfil; pero mientras Egipto era codiciado como colonia, Grecia había ganado ya su derecho a una independencia nacional. No debemos olvidar, por otra parte, que en el tiempo que dista entre la expedición de Egipto y la de Morea se ha producido en el contexto intelectual europeo un giro copernicano respecto a la valoración del antiguo Egipto respecto a su aportación a la civilización universal, no sólo por el filohelenismo triunfante, sino también por lo que Martin Bernal ${ }^{12}$ ha denominado la sustitución del «paradigma antiguo" por el "paradigma ario» y que se opera principalmente a raíz del desarrollo filológico en el que se enmarca el desciframiento de la escritura jeroglífica. Con Argelia hablamos ya de una colonia francesa, por lo que el estudio arqueológico e histórico queda relegado por un interés eminentemente práctico de conocer la realidad social y natural como clave de una

11 Cf. DHомвREs, Jean et Nicole, Naissance d'un nouveau pouvoir: sciences et savants en France (1793-1824), París 1989. La obra de Dhombres explora, además, algunos de los desarrollos en las relaciones ciencia-poder y en la configuración de los diferentes paradigmas alternativos de la ciencia francesa del periodo a los que hemos venido haciendo referencia en este trabajo.

12 BERNAL, Martín, La Atenea Negra, Barcelona 1993.

Hispanja, LVI/, núm. 192 (1996) 77-92 
colonización más efectiva. Todo ello condiciona los dispositivos cientificos que entran en operación, aspecto que abordaremos a continuación, pero éstos a su vez pueden provocar una integración de los espacios, si no cultural al menos física, del Mediterráneo.

Al abordar los dispositivos científicos puestos en ejercicio por las tres expeciones, un primer punto a estimar es el del movimiento de equipos sobre el terreno, aspecto sobre el que ya hemos avanzado algunas indicaciones.

La comisión científica en Egipto poseyó una base institucional de operaciones: el Institut d'Egypte, en cuyo marco se proponía al cuerpo savant la constitución de comisiones específicas para abordar diversas cuestiones en función de las necesidades puntuales de la campaña o del proyecto más general de un inventariado total del país en el que debían quedar integrados la topografía, la hidrología, los recursos naturales, la flora y la fauna, las actividades económicas y empresariales, los sistemas legislativos, etc. No obstante, el establecimiento de dichas comisiones no condicionó en absoluto el movimiento de los savants sobre el terreno y el objeto principal de sus investigaciones. Los miembros de la comisión aprovechaban los movimientos militares para acceder a sus objetos de estudio, como en el caso de Vivant Denon y su exploración de los momumentos del Alto Egipto acompañando a Desaix en su persecución de los mamelucos. En otros casos, el encargo de una determinada misión de reconociminiento científico tranformaba sus resultados más destacados, gracias al tesón y sacrificio de sus protagonistas, en algo muy diferente a su objetivo inicial: asf lo muestran los dos jóvenes ingenieros, Jollois y Devilliers, a quienes debemos un análisis exhaustivo de los momumentos del Alto Egipto. Dicho trabajo fue realizado en el tiempo que podían escatimar a sus labores en el seno de la comisión hidrográfica al mando de Girard que tenía como objeto y reconocimiento completo del sistema hidrográfico del Nilo y los sistemas de irrigación, aunque subsidariamente debía recoger la mayor información posible sobre comercio, agricultura, artesanía, historia natural, geografía y antigüedades. El mismo caso encontramos en otros jóvenes ingenieros, como Chabrol, que como participante en la ardua y prolongada labor de nivelación y reconocimiento de la zona de Suez dirigida por Le Père para determinar la posibilidad de la apertura del mítico canal realiza un admirable estudio etnográfico sobre las tribus árabes de la zona. El mismo reconocimiento inicial de la zona, encabezado por el propio Bonaparte, había atraído a la élite más destacada de la expedición que utilizó el viaje para sus respectivos trabajos. Como en este caso, en numerosas ocasiones los savants seguían a los ingenieros en sus trabajos para realizar estudios determinados que, en la mayoría de los casos, respondían a preocupaciones gestadas en Francia: esta fue la pauta principal de los naturalistas o de químicos como Berthollet. No obstante, algunas de las comisiones de exploracion establecidas funcionaron como tales: las dos expediciones del Alto Egipto, una dirigida por el matemático Costaz y la otra por Fourier, constituidas a rafz de la admiración que los dibujos de Vivant Denon provocaron en el Instituto, congregó en una tarea conjunta a los miembros más 
destacados de la comisión, labor a la que se sumaron también los naturalistas. Asímismo, un trabajo considerable se realizó en las ciudades ocupadas por el ejército francés. Los resultados de los diversos trabajos eran presentados en las sesiones del Institut y la mayoría de ellos iban apareciendo en la Décade Egyptienne, uno de los dos periódicos publicados durante la campaña y órgano de expresión del Instituto. Sus páginas muestran la diversidad y amplitud de los aspectos abordados y el carácter pluridisciplinar de las comisiones constituidas. Éstas abordaban con la misma disposición cuestiones relacionadas con la fabricación de la cerveza, estudios de sistemas comparados de pesos y medidas, el reconocimiento de los lagos de natrón... Y los savants presentaban memorias relativas a sus trabajos específicos en el marco de las comisiones así como de aquellos que desarrollaban en las líneas de investigación que les caracterizaban en Francia. Estas memorias, sin embargo, dejan ver en pocas ocasiones la forma de trabajar sobre el terreno tanto de miembros de comisiones militares y civiles como de científicos individuales, ya que eliminan el proceso de descubrimiento y la referencia al actor en su escenario. Tan sólo algunos libros de viajes iluminan el estudio al respecto ${ }^{13}$.

Diferente fue el caso de la expedición de Morea. Con el cuartel general de la Comisión instalado en Modon, a cada sección se le asignó una casa confiscada por el ejército. A partir de allí, las secciones se dividían en pequeños grupos con el fin de cubrir lo más rápidamente la zona. En las secciones de arquitectura y escultura y arqueología pronto triunfa la indisciplina, situación agravada por la enfermedad y retirada de Dubois, el director de esta última. Así, la expedición se convierte para ellos, en palabras de alguno de sus miembros, en un viaje pagado a Grecia. El rigor científico no guía los objetivos de su estancia en Morea, pues como dirá Blouet al presentar el segundo volumen del trabajo desarrollado: «Esta obra no es la de un anticuario o un cientifico, sino la narración exacta y concienzuda de un viaje acometido por artistas a la patria de las bellas-artes» ${ }^{14}$. La memoria científica cedía de nuevo terreno ante espíritu que animaba el libro de viaje. Bory de Saint-Vincent consigue, por el contrario, hacer reinar la disciplina en su grupo de trabajo. Escindiéndose en pequeños grupos, que se reunen periódicamente, Bory viaja habitualmente con el geólogo Virlet, el zoólogo Brullé (entomólogo) y el dibujante Baccuet; Pullon-Boblaye y Delaunay (zoólogo), por una parte, y Despréaux (botánico) y Pector (zólogo), por otra, se encargan de recorrer otros sectores, lo que permite cubrir todo el país en poco tiempo. El trabajo principal consistirá en la recogida de especímenes que posteriormente serán clasificados en Francia con la ayuda de naturalistas sedentarios y de las publicaciones necesarias. Tras seis meses de trabajo, las fiebres hacen que la comision embarque con rumbo a Francia, dejando sobre el terreno a los ingenieros geo-

13 Tal es el caso de las memorias dejadas por los jóvenes ingenieros antes aludidos. JoLLots, Prosper, Journal d'un ingenieur attaché à l'expédition d'Egypte, Paris 1904; De VILLIERS du TERRAGE, Edouard, Journal et souvenirs sur l'expédition d'Egypte, París 1899.

14 Citado por Peltre, Christine, op. cit., pág.8.

Hispania, LVIf, núm. 192 (1996) 77-92 
gráfos quienes, organizados en brigadas topográficas, consiguen la realización de un trabajo admirable en poco tiempo.

En Argelia los grupos de trabajos se constituyen, como ya apuntábamos, según división territorial: sección litoral, sección interior, sección nómada. Esta división refleja en cierta medida la articulación de la expedición en los proyectos de fortalecimiento de la colonización francesa del territorio argelino: en el pensamiento y la política coloniales respecto a Argelia comienza a ponerse en cuestión la posibilidad de "colonizar" todo el territorio y, por ende, de "asimilar» a toda la población. Así, comienza a proponerse el establecimiento de una colonización restringida y de una división del territorio con diferentes formas de gobierno colonial: un territorio, el correspondiente al litoral y las zonas urbanas, sometido a la colonización europea con un gobierno civil; otro, el interior, dejado a los árabes y administrado por los militares que mantedrían para su provecho el sistema tradicional ${ }^{15}$. Así el reagrupamiento de los participantes de la expedición se realiza según los caracteres de los espacios a conquistar. A su llegada a Argel, todos se reagrupan en torno a Bory de Saint-Vincent, quien seguía imponiendo su displina como en Morea. Siempre acompañados por columnas militares, la exploración se hace sumamente costosa. En las regiones del Sur, por ejemplo, donde aún el territorio no ha sido pacificado, deben contentarse con la información suminis. trada por los indígenas, por la encuesta, que resultará sufiente para el desarrollo de la parte de geografía crítica acometida por la expedición. La jerarquía, de corte militar, reina en los grupos de exploración, resultado en alguna medida de la deficiente formación de algunos de los miembros de la comisión, como en el caso de simples preparadores del Museo de Historia Natural.

Las informaciones recogidas por los 20 miembros de la expedición serán inventariadas, clasificadas por oficiales, funcionarios y científicos de la metrópoli.

No obstante, los dispositivos científicos principales de construcción vendrán constituidos por el papel de las diferentes disciplinas en el marco de las expediciones y en sus métodos de análisis de la realidad encontrada. Puesto que sería muy extenso una relación siquiera somera del desarrollo de cada disciplina en el marco de cada expedición, hemos optado por rescatar algunos dispositivos de lectura de la realidad con los que los expedicionarios franceses se dotaron en su labor de inventariado y clasificación, y en la que quedan integradas diferentes disciplinas.

Posiblemente la mirada topográfica sea la que mejor pueda definir el bagaje científico-instrumental utilizado. En ella van a quedar apresados no sólo los trajabos propiamente topográficos y geográficos, de crucial importancia en las tres expediciones, sino la medicina, la historia natural, la descripción etnográfica y la historia.

15 Véase, por ejemplo, LAuRENS, Henry, Le royaume impossible: la France et la genèse du monde arabe, Paris 1990, cap.3. 
Comenzando por la primera, la medicina, Michael Osborne ${ }^{16}$ ha mostrado cómo la coyuntura constituída por el desarrollo de la teoría biológica transformista - con su atención a la relación entre el entorno y el organismo-y la resurrección de la teoría médica hipocrática -más concretamente la reconstrucción y reinvención de la misma en manos de Littré, quien deshistorizándolo lo acercaba a los higienistas modernos- representa el marco de lo que va a ser la principal tradición médica del ejército francés en el siglo XIX: la topografía médica. Así, el hipocratismo médico, especialmente el estudio epidemiológico y la doctrina climática hipocrática, tuvo una influencia primordial en la mayor parte de los trabajos médicos e higiénicos de las tres expediciones. Como método epidemiológico, el hipocratismo médico obligaba a una cuidadosa cartografía de los entornos de la enfermedad y aconsejaba evitar localidades, personas y objetos asociados con ella. La geografía médica imponía la observación y descripción de las características meteorológicas, dietéticas y geografícas en relación con la salud, los hábitos, las razas y el caracter de los habitantes de la región.

En Egipto, será Desgenettes, médico en jefe de la expedición, formado en el hipocratismo del xviI de la escuela de Montpellier, quien mejor represente esta corriente, frente a su colega Larrey, cirujano en jefe, que se ocupará del tratamiento de las enfermedades. La primera intervención de Desgenettes en el Institut d'Egypte ${ }^{17}$ consiste precisamente en las instrucciones a todos los médicos del ejército para la redacción de una topografía física y médica de Egipto como única clave para la aplicación de principios higiénicos y para el hallazgo de medicamentos eficaces: así todos ellos deberían consignar para cada zona de estudio la naturaleza del suelo, la longitud y la latitud, los vientos dominantes, principales cualidades físicas de las aguas del Nilo, pozos y cisternas y su influencia en la vegetación y la salud de los habitantes, las especies vegetales más abundantes, los cultivos y sus enfermedades, las sustancias médicas con las que se comercia, los animales y sus enfermedades, el temperamento general de sus habitantes, su alimentación, vestido, ocupación, costumbres, enfermedades más comunes en los diferentes sectores de la población, etc. A falta de una sección específica en la Description d'Egypte tan sólo algún trabajo aislado se introduce en la parte dedicada al Etat

16 OSBORNE, Michael, (The medicine and hygiene of the expeditions to Egypte, Morea and Argelia», ponencia presentada al seminario L'invention scientifique de la Méditerranée: Egypte, Algérie, Morée, Paris VII, marzo 1993. Véanse también otros trabajos del mismo autor centrados en las teorías de aclimatación y su articulación en Jas politicas coloniales en Argelia, que han quedado asumidos en su reciente obra: OsBORNE, Michael, Nature, the Exotic, and the Science of French Colonialism, Indiana 1994. Igualmente interesante es el trabajo de LA BERGE, «The conquest of Argeria and the discourse of public bealth in Francen: LAFUENTE, A., ELENA, A. y ORTEGA, M. L. (editores), Mundialización de la ciencia y cultura nacional, Aranjuez 1993, págs. 539-544.

17 "Lettre circulaire du citroyen Desgenettes aux médecins de l'armée d'Orient, sur un plan propre à rédiger la topographie physique et médicale d'Egypte", recogida Mémoires sur l'Egypte, Paris 1801 , obra que reimprime parte de las actas de las sesiones del Institut y de los trabajos ya publicados en la Décade Egyptienne.

Hispania, LVIL, núm. 192 (1996) 77-92 
Moderne-, los resultados de tal encuesta general se repartirán entre las memorias presentadas al Institut y la obra publicada por Desgenettes Histoire médical de l'Armée d'Orient ${ }^{18}$.

En la expedición de Morea, la medicina estuvo muy poco representada, adquiriendo de nuevo un papel destacado en Argelia. Con el Dr. Périer la geografía médica se convierte en hegemónica, así como en la clave de ciertas acciones sanitarias -como la plantación de eucaliptus que se convertirán en símbolos del poder francés para que la civilización triunfe sobre la barbarie. Pero una característica distingue la experiencia argelina: mientras en Egipto y Morea botánicos y médicos encuentran principalmente lo familiar -en el primero de los casos remitiéndose a las experiencias de otras campañas napoleónicas-, en Argelia la medicina tiende a «exotizar» el país para aplicar los criterios de medicina colonial: la cuestión principal será ahora la aclimatación de la raza europea, posible desde la posición eminentemente asimilacionista de Périer, mediante la conversión de ésta a las formas de vida nativa y practicando el maridaje con la población argelina ${ }^{19}$.

Por lo que a la historia natural se refiere, podríamos señalar dos casos en los que la mirada cartográfica y geográfica se impone, aunque de manera diferente: en el primero se convierte en un disposivo expositivo; en el segundo en dispositivo de carácter heurístico disciplinar.

A diferencia de la preocupación de sus compañeros naturalistas, Etienne Geoffroy Saint-Hilaire y Savigny, por integrar sus trabajos sobre los especímenes zoológicos recogidos en Egipto en un marco teórico dominado por el paso de la sistemática a la morfología comparada, el ingeniero de minas Rozière ${ }^{20}$ realizó un admirable trabajo mineralógico sin un referente teórico hegemónico: en él la mirada topográfica se impondría como recurso expositivo. La mineralogía, a caballo aún entre la historia natural y la nueva displina de la geología, carecía por el momento de una clasificación exacta y de una nomenclatura fijada. Rozière dedicó, por ello, un gran esfuerzo en la elaboración de las planchas: el dibujo sería la clave para el reconocimiento de la forma particular y el volúmen, el color y las texturas, mientras la descripción proporcionaría una indicación de los elementos constitutivos. Así el dibujo tomaba, como lo hará en toda la sección de Histoire Naturelle y en buena parte de la sección de Antiquités de la Description de l'Egypte, el protagonismo. Una vez terminadas las planchas, las ilustraciones que contenían no se presentaron siguiendo el orden de cualquier sistemática mineralógica, sino ofreciendo la distribución misma de los objetos en Egipto, desde Assuan, descendiendo por el Nilo y dirigiéndose hasta el Mar Rojo, ordenación que retóricamente correspondía al recorrido realizado por las

18 Desgenettes, René-Nicolas, Histoire médical de l'Armée d'Orient, Paris 1802.

19 Estas consignas asimilacionistas desparecerán del pensamiento de Périer en la década de 1960 en clara consonacia con el cambio de rumbo de la política colonial francesa hacia posiciones más cercanas al asociacionismo.

20 Sobre el trabajo de Rozière durante la expedición véase: GLlispiE, Charles C., «Aspects scientifiques de l'Expédition d'Egypte (1798-1801)»: Laurens, Henry, L'Expédition d'Egypte, Paris 1989, págs. 385-387. 
comisiones de exploración de Alto Egipto descendiendo el Nilo, así como el orden en el que se encuentran dispuestas las planchas y descripciones de Antigüedades. Al fin y al cabo, como lo expresaba el propio Rozière, la Description de l'Egypte debía tener por objeto un conocimiento completo del país. El mismo Rozière redactará trabajos mineralógicos de diferentes regiones y, principalmente, una memoria sobre «la constitución física de Egipto», en la que un estudio de la geografía física del país se convierte en toda una tesis acerca de cómo la civilización se ve condicionada por sus condiciones materiales: el conocimiento del estado físico de Egipto nos iluminaría sobre las teogonías, las artes, los sistemas de medidas y estilos de calendario, las concepciones físicas y astronómicas no sólo de los antiguos egipcios, sino de los pueblos de oriente, Grecia y de la Antigua Europa que los tomaron como modelo.

Esta posición no es en absoluto un caso aislado en la expedición de Egipto: como decíamos la mirada geográfica y la historia o la arqueología se interfecundan constantemente en sus trabajos. La labor de localización de los enclaves faraónicos ${ }^{21}$ recurrirá constantemente a la geografía comparada o histórica, mientras la exploración geográfica y geológica del terreno llevan a poner en entredicho las afirmaciones de las autoridades clásicas acerca de las transformaciones sufridas, por el ejemplo, en el cauce del Nilo y su relación con diferentes enclaves antiguos de civilización.

El segundo caso que desearíamos citar respecto a la historia natural es el de la labor botánica de Bory de Saint-Vincent realizada en Morea, analizada por Jean-Marc Drouin ${ }^{22}$. Entre la expedición de Egipto y la de Morea, la historia natural había experimentado el desarrollo de las ideas de Humbold y de Candolle que darían toda su dimensión a la geografía botánica. Antes de su participación en la expedición. Bory de Saint-Vicent había manifestado en algunos de sus trabajos su acuerdo con la obra de de Candolle, aunque frente a él considerase la aparición sucesiva de nuevas especies por generación espontánea y sus modificaciones bajo la influencia de diversas causas locales. Así, a la hora de inventariar los especímenes recogidos en Morea para su publicación en 1832, adopta tres criterios metodológicos que dan a su trabajo un caracter original: el uso del sistema linneano (no excepcional en la Francia de la época, pero tampoco usual), el rechazo a multiplicar especies subdividiéndolas sobre la base de pequeñas diferencias y el lugar de la geografía botánica. Afirmaba la necesidad de apoyar la geografía botánica sobre el registro de las condiciones locales, lo que imponía un estilo de trabajo sobre el terreno determinado que permitiera una completa descripción del hábitat. Ello, a su vez, le permitía relacionar la composición florística de Morea a la encontrada en la Italia meridional y la España bética, mientras la físionomía

21 Cf. Forgeau, Annie, «Le repérage des sites de l'Egypte pharaonique par les membres de la Commission des sciences et des arts", ponencia presentada al seminario L'invention scientifique de la Méditerranée: Egypte, Algérie, Morée, Paris VII, mayo 1993.

22 Droun, Jean-Marc, «Bory de Saint-Vincent et la géographie botanique», ponencia presentada al seminario L'invention scientifique de la Méditerranée: Egypte, Algérie, Morée, Paris VII, febrero 1993.

Hispania, LVII, núm. 192 (1996) 77-92 
de la vegetación remite a la de la Francia meridional. Esta imagen tendente a la integración de la naturaleza y el paisaje mediterráneos no es, como ya señalamos, una característica común. Como dijimos, en Argelia siempre encontraremos una tensión no resuelta entre los "exótico», ejemplificado en la medicina, y lo "familiar", principalmente reflejado en la historia natural.

Respecto a las ciencias humanas, la expedición de Egipto vuelve a ofrecer la prevalencia de esta mirada topográfica sobre la realidad. Tan sólo señalaremos que la mayor parte de las memorias contenidas en la sección del Etat Moderne de la Description, que dan cuenta de numerosos aspectos sociales, industriales, políticos y económicos del Egipto moderno, fueron redactadas si no literalmente en contestación al cuestionario redactado por Jacotin y destinado a los ingenieros geógrafos para la confección de la carta general de Egipto, sí respondiendo al mismo espíritu que manifestaba la encuesta: la representación científica del Egipto moderno tomaba la forma de un mapa cartografico y textual que supusiera un inventariado y una localización espacial del territorio, sus gentes y sus productos culturales. Como ha mostrado el estudio de Anne Golewska ${ }^{23}$, el conjunto de trabajos que constituyen la Description sería una colección inconexa si sus memorias y grabados no estuvieran interrelacionados por una red de signos que las remiten constantemente a planos y mapas.

No podríamos terminar este trabajo sin hacer cuando menos una breve referencia al universo de pensamiento que realmente construye en este periodo una imagen integrada del Mediterráneo y que además está presente en Egipto como heredero de la expedición y en Argelia como elemento integrante de su exploración y del proyecto colonial: nos referimos sin duda al movimiento Saint-Simoniano.

Una serie de artículos firmados por Michel Chevalier en Le Globe a partir de 1832 bajo el título "Systeme de la Méditerranée» marcan el inicio de esta construcción. En ellos se muestra cómo el destino político e industrial de Europa se encuentra en el mar que une Oriente y Occidente. De ahí su plan de un Sistema general de ferrocarriles, canales y puertos que harán del Mediterráneo «el lecho nupcial entre Oriente y Occidente», esta confederación mediterránea se abrirá a otras partes del mundo por las aperturas de Suez y Panamá: el mundo será un solo cuerpo recorrido por una circulación ininterrumpida de hombres y mercancías. A este plan general responderá el viaje de los saint-simonianos al Egipto de Muhammad Ali entre 1833-1836 que para algunos se convertirá en una estancia más prolongada - Lambert se convertirá en director de la Escuela Politécnica y Linant de Bellefond en director de Obras Públicas. Sin embargo, el "pachá industrial», expresión con la que se referían a Muhammad Ali, en cuyas políticas veían una anticipación de algunas de sus propuesta reformistas - colectivización de tierras,

23 GODLEWSKA, Anne, «Measuring, mapping and sketching. The mentality of Enlightement conquerors: A new look at the Description de l'Egyptes, ponencia presentada al seminario $L$ 'invention scientifique de la Méditerranée: Egypte, Algérie, Morée, Paris VII, abril 1993. 
movilización de instrumentos de producción, anulación del derecho hereditario, desarrollo industrial como impulsor de la regeneración social-pronto hará fracasar sus esperanzas de la operación industrial modelo en torno a la apertura del canal de Suez, al negarse a emprender los trabajos para su consecución, y por ende del "sistema mediterráneo" que reconcile Oriente y Occidente organizando produccion e intercambios en el marco de una división internacional del trabajo. La mirada de Enfantin se dirigirá por tanto a Argelia, donde será ahora "colonización" el termino a redefinir. No obstante, sus periplos de los saint-simonianos por el Mediterráneo resultarán en la formación de unas redes informales de "adeptos» a principios muy generales de la doctrina que continuarán reflexionando sobre la integración de ese mar común, pero ya desde fuera de los márgenes de la ciencia política y sociamente sancionada en Francia. 